\title{
JEAN-PAUL SARTRE E MICHEL FOUCAULT: DO DESENCONTRO HUMANISTA À CONFLUÊNCIA DA LIBERDADE (ENGAJAMENTO E CUIDADO)
}

\author{
Guilherme Roman Borges \\ Doutor em Filosofia e Teoria Geral do Direito \\ pela Faculdade de Direito da Universidade de \\ São Paulo.
}

Resumo:

Não-obstante as rusgas teóricas iniciais entre Jean-Paul Sartre e Michel Foucault, em razão da fílosofia marxista, inúmeras questões ressaltam o proficuo encontro entre os dois grandes intelectuais franceses do século XX. Se de um lado a problemática do "humanismo" os distanciava profundamente, a questão da "liberdade" os aproximava e os colocava em busca de uma constituição política do homem moderno. Nesse sentido, procurando-se evidenciar a relação acadêmica entre os autores, através daqueles conceitos, é que estas linhas adiante se debruçam.

Abstract:

Due to theoretical disagreements between Jean-Paul Sartre and Michel Foucault, in reason of the marxist philosophy. innumerable questions stand out a good meeting between the two great French intellectuals of the $20^{\text {h }}$ century. If on one side the problematic of the "humanism" put them far away deeply, the question of the "freedom" approached them and it placed them in search of a constitution politics of the modern man. In this direction. this text covers the academic relation between the authors.

Unitermos: Humanismo; Liberdade; Fngajamento: Cuidado de si.

Keywords: Humanism. Freedom, Enrollment, Care of itself.

1. Os intelectuais franceses e a relação na Rue d'Ulm.

Michel Foucault assistiu às aulas de Jean-Paul Sartre na Rue d'Ulm, e dirigiu suas peças de teatro, realizadas pelos alunos de Uppsala, entre os anos de 1955 
e 1957. sobretudo Les Mains Sales.' Entretanto, no início de sua vida acadêmica, antes de reconhecer o brilhantismo e a importância do grande filósofo, Foucault procurou lutar e negar imensamente a contribuição de Sartre, a tal ponto que chegara a afirmar, na manhã de 19 de abril de 1980 para Catherine von Bülow, no funeral de Sartre, que "quando eu era moço queria me livrar dele, de tudo que ele representava, do terrorismo de Les Temps Modernes." Foucault também havia ficado decepcionado com a revista, quando não divulgaram nenhuma nota por ocasião da publicação de sua clássica obra Histoire de la Folie, o que o marcara profundamente.

Entretanto, como afirma Didier Eribon, apesar das aulas da Rue d'Ulm e do encontro casual do dia 10 de fevereiro de 1969, entre Foucault e Sartre. durante o comício na Mutualité, após a evacuação de Vincennes (que acabou não sendo profícuo dado o contingente de pessoas), foi somente no dia 27 de novembro de 1971, enquanto Foucault discutia com Claude Mauriac e Jean Genet os preparativos para uma movimentação pública em prol da luta contra o racismo, que o velho grande mestre e o jovem grande filósofo se encontraram pela primeira vez. ${ }^{3} \mathrm{O}$ encontro teria sido em virtude do assassinato do jovem Djellali Ben Ali, um argelino que teria maltratado uma vigia de um prédio na Goutte d'Or, um bairro de Paris, e em seguida morto por um amigo desta. Apesar da pequena comoção inicial, alguns grupos se reuniram no bairro para protestar, e Foucault resolveu criar uma comissão de inquérito sobre as condições de vida na localidade, juntamente com Gilles Deleuze. Jean Genet, Claude Mauriac, Jean-Claude Passeron e outros. Junto ao grupo, outros intelectuais, como Michel Leiris, Yves Montand, Simone Signoret e, especialmente, Sartre, protestaram pelas ruas parisienses. Sobretudo Foucault e Sartre, que com megafones, tal a foto que imortalizou este momento, anunciaram que no dia seguinte estariam de vigília na Igreja Saint-Bruno, para ajudar aos imigrantes ilegais a preencher os formulários necessários. Ambos defendiam e sempre defenderam os mesmos objetivos, como a preferência pelos israelenses aos palestinos, em suma, pela "liberdade"

1. ERIBON, Didier. Michel Foucault. (trad. Hildegard Feist). São Paulo: Companhia das Letras, 1990 , p. 91.

2. ERIBON, Didier. Michel Foucault.. p. 260.

3. ERIBON, Didier. Michel Foucault., p. 222-223. 
Após serem vistos Foucault e Sartre nas lutas políticas em defesa sobre a realidade da União Soviética, sobretudo nos debates com os dissidentes dos países do Leste, juntamente com outros intelectuais franceses, Raymond Aron, André Glucksmann, Simone de Beauvoir, Sartre e Foucault se encontram pela última vez em 20 de junho de 1979, antes da morte do literato, para compactuar com uma última discórdia internacional, em prol dos boat people, refugiados vietnamitas que fugiam de seu país, pelos quais vão brigar junto às autoridades francesas para thes exigir que aumentem o número de refugiados autorizados a se instalar na França. Hm 19 de abril de 1980, Sartre é sepultado, terminando, ao menos no campo político e afetivo, a profícua relação entre os dois grandes filósofos. ${ }^{4}$

2. Das diferenças do humanismo ao encontro da liberdade interior: de Foucault a Sartre.

As discórdias e as semelhanças de pensamento, tal fora o caminho de vida, marcam as relações intelectuais entre Michel Foucault e Jean-Paul Sartre, dois filósofos de renome que foram capazes de escrever a história da segunda metade do século passado. Deste modo, inúmeros aportes teóricos podem ser feitos entre Foucault e Sartre, tal como muitos autores o fazem, a ver Mark Poster, John Rajchman. Elkabbach, etc.

Mark Poster, ${ }^{5}$ ao estudar a presença do marxismo questionado na obra foucaultiana, deixa-se formular vastas considerações sobre a relação entre Sartre e Foucault. demonstrando princípios de coincidência e desavenças teóricas; nesse sentido, elenca vários, a começar pelos negativos, os pontos de desencontro: a) para o autor, no início dos anos 60, a aproximação da corrente estruturalista por Foucault era inconciliável com as concepções teóricas de Sartre, cuja figura central residia justamente no homem e seus modos de exercício: b) destaca que as concepções iniciais de Foucault se opunham radicalmente às tendências do existencialismo sartreano, uma verdadeira antítese de todas as filosofias da consciência, já que Foucault entendia ser necessário evitar uma noção de sujeito transcendental e alheio

4. ERIBON, Didier. Michel Foucault., p. 259.

5. POSTER, Mark. Foucault, el marxismo y la historia. (trad. Ramón Alcalde) Barcelona: Paidós, 1987. p. 13-98. 
às mudanças ao longo do tempo, noção essa visível nas últimas obras sartreanas; c) o problema da totalização os diferenciava significativamente, posto que, enquanto Foucault estava tão preocupado em limitar o alcance da posição epistemológica, que se negava a sistematizar a sua própria posição, bem como desenvolvia seus próprios conceitos para se negar a analisar de qualquer modo a posição que ele chegava ao conhecimento, de maneira excessivamente positivista; Sartre sc postava de modo diametralmente oposto, isto é, considerando o marxismo tão necessitado de claridade epistemológica, baseou todo o edificio da teoria crítica sobre o ato do conhecimento, de tal forma que, como a consciência é livre ou indeterminada, o indivíduo totaliza seu projeto, com o qual o esforço do conhecimento retorna em última instância à necessidade que tem o indivíduo de eleger um curso de ação; ${ }^{6}$ d) por fim, destaca que outra diferença é a questão do objeto, pois o interesse principal de Sartre está situado na subjetividade, isto é, de que maneira os seres humanos podem reconhecer e realizar sua liberdade dentro da totalização que se cumpre na história; o que importa, de fato, é o destaque aos obstáculos que os sujeitos encontram no seu esforço por se autoreconhecerem; de outro lado, Foucault privilegia a objetividade como campo e investigação, ao procurar tornar inteligiveis os modos de dominação ou as tecnologias de poder que haviam escapado da atenção do marxismo clássico (todavia, o autor alerta para o fato de que a preocupação pela resistência e a análise da dominação são complementares e não-necessariamente contraditórias). ${ }^{7}$

Em contrapartida, o autor americano também ressalta, alguns pontos positivos, que devem ser elencados: a) para o autor, a critica da razão ocidental oferccida por Foucault em Histoire de la Folie estava muito próximo do modo como se estabelecia o anticientificismo de Sartre e Merleau-Ponty, especialmente pela proximidade do Partido Comunista nos primeiros anos do pós-guerra; b) destaca que, igualmente a Foucault, Sartre questionou o conceito cartesiano de sujeito racional, enquanto fundamento epistemológico e ontológico da realidade, quer dizer, tal os

6. É importante destacar que o próprio Foucault, quatro anos após u movimento estudantil, mesmo reconhecendo a importância do grande Sartre, não podia deixar de ver algumas diferenças, tanto que, nesse sentido, juntamente com Deleuze, opõe a idéia de um intelectual total de Sartre uma viš̃o de um intelectual especifico: DELEUZE, Gilles. Les intellectuels et le pouvoir: entretien avec Michel Foucault. Dits et Écrits (org. Daniel Defert et François Ewald). Paris: Gallimard, v. 2, 1994, p. 306-315. [urad, br. Os intelectuais e o poder. Microfisica do poder. (trad. Roberto Machado) 13 ed. Rio de Janeiro: Graal, 1998. p. 69-78.]

7. POSTER, Mark. Foucault, cl marxismo .... p. 45. 
estruturalistas, o autor de Le Mur se mostrava na mesma oposição que o filósofo francês se pôs contra a tradição metafísica ocidental; c) o resgate de Nietzsche operado por Sartre, especialmente no que tange à idéia de um conhecimento limitado à perspectiva que cada indivíduo brinda com sua posição histórica e social, fazia Foucault creditar as opiniões intelectuais do autor; d) ambos concordam, apesar da diferença da totalização, supra-abordada, que o teórico tinha uma posição decisiva para o conhecimento que desenvolvia; e) por fim, destaca que o grande questionamento de semelhança seria em relação ao status do sujeito, quer dizer, enquanto para Foucault a consciência individual é metodicamente excluída enquanto objeto de conhecimento, Sartre também se opõc ao idealismo acadêmico francês, para o qual o sujeito racional era um centro metafísico; tal como Foucault, Sartre emprega categorias sociais e históricas para destacar as transformações nos modos de subjetividade.

A polêmica entre os autores, entretanto, começa a ser suscitada no início da década de 60, desde que Les Temps Modernes não-comentara a aparição de Histoire de la Folie. Na tesc menor não-publicada e apresentada em 1961 por Foucault sobre a antropologia de Kant, era possivel identificar um ataque direto às tentativas contemporâneas de fundar uma antropologia, especialmente na esteira de Sartre e Merleau-Ponty. ${ }^{8}$ Do mesmo modo, Raymond Bellour, que teve a chance de ler o manuscrito de Les Mots et les Choses, mesmo antes de sua publicação, afirmara. certa vez, nas discussões sobre a palestra de Gérard Lebrun, durante o famoso seminário intitulado Michel Foucault, Philosophe, realizado em Paris (janeiro de 1988), e coordenado por Canguilhem, que nele havia inúmeras críticas de Foucault a Sartre, mas que foram suprimidas, para evitar maiores polêmicas."

Foucault tem oportunidade de responder em La Quinzaine Littéraire da primeira metade de março de 1968 as críticas efetuadas por Sartre, trançando-lhe iguais desavenças. Segundo Foucault, Sartre erra em vários pontos: primeiro, quando o coloca junto aos estruturalistas, o que seria incoerente. já que o estruturalismo não

8. ERIBON, Didier. Michel Foucault..., p. 160.

9. BELLOUR, Raymond. in LEBRUN, Gérard. Nota sobre la fenomenología contenida en las palabras y las cosas. Michel Foucault, filosófo. (tad. Alberto Luis Bixio) Barcelona: Gedisa, 1999 p. 47. "Raymond Bellour señala a manera de respuesta que páginas referentes a Sartre fueron suprimidas de la versión definitiva de Lus palabras y las cosus" [trad. do autor "Raymond Bellour destaca em sua resposta que páginas referentes a Sartre foram suprimidas da versão definitiva de As Palavras e as Coisas."] 
era um grupo único e coeso, de mesmas perspectivas; em segundo, que Sartre é um homem imensamente mergulhado nas suas diversidades teóricas, como a literatura, a filosofia, a política, etc., e que não teria tido tempo de ler a sua obra; e, por fim, que Sartre, no próprio Partido Comunista, era visto como o último dos imperialistas burgueses, não tendo tanta importância como se via. ${ }^{10}$ De outro lado, Eribon comenta a postura de Sartre ao desconsiderar a opinião de Foucault sobre a justiça popular como um ato de violência: "Não concordamos, os muoístas e eu por um ludo e ele por outro. Achamos que o povo pode muito bem criar uma corte de justiça ... Foucuult é radical: toda forma de justiça burguesa ou feudal pressupõe o tribunal, a corte, os juizes atrás de uma mesa ... A justiçu implica primeiro um imenso movimento que derruba as instituições. Mas, se durante esse grande movimento aparece a forma de justiça revolucionária, ou seja, se se pergunta às pessoas, em nome da justiça, que prejuizos sofreram, não vejo que mal há em se fazer isso com gente sentada atrás de uma mesa ou não"."

Todavia, a par das constantes polêmicas que envolveram os intelectuais, aprouve-se por bem demonstrar duas grandes questões capazes de ora distanciar os intelectuais, especialmente no que tange a uma filosofia humanista, ora de aproximar, no que se refere à temática da liberdade. É. nessa perspectiva, que doravante se debruça este texto.

Dessa mancira, a relação entre o pensamento de Sartre e Foucault pode ser estabclecida em torno de dois conccitos fundamentais, aproximativos o distanciadores: "humanismo" e "liberdade" O tema do humanismo, tanto criticado por Foucault, faz distanciá-lo significativamente de Sartre, a ponto de tecer-lhe duras críticas, já que o autor, com seu método existencialista, sobretudo na clássica conferência L'Existentialisme est un Humanisme, defende a inserção de sua teoria junto a essa tendência. Coincidentemente, esse é o momento um que o magistral filósofo está completamente distante pessoalmente de Foucault, até porque Foucault havia recém ingressado na École Normule, quando o texto fora publicado em 1946. Fm contrapartida, o tema da liberdade, que constitui scm dúvida o cerne do pensamento sartreano, destacado a partir de 1943, com l.'Étre et le Néant, traz

10. ELKABBACH, Jean-Pierre. Fuucault répond à Sartre. Dits et Écrits (org. Daniel Defert et François Ewald). v. I Paris: Gallimard, 1994, p. 662-668.

II. ERIBON. Didier. Michel Foucault., p. 229. 
profundas correlações ao conceito de liberdade que Foucault desenvolveu nos seus últimos anos de vida, especialmente a partir de seus derradeiros volumes da história da sexualidade e a do cuidado de si. Já nessa época, um pouco antes destes últimos ensaios sairem, e antes da morte de Sartre, é o momento em que, na vida pessoal, o jovem filósofo reconhece a magnitude do pensamento sartreano e sua importância nas lutas políticas.

Entretanto, antes de abordar mais detalhadamente esse encontro feliz, que aproxima os filósofos da École, em torno do conceito de liberdade, convém compreender o embate inicial em torno da filosofia humanista, isto porque Foucault criticara sensivelmente a perspectiva humanista, especialmente em Les Mots et les Choses, enquanto Sartre defendia claramente, na referida conferência proferida no Club Maintenant em 1946, a identidade do existencialismo como uma forma de humanismo. Nesse texto, Sartre afirma que o existencialismo se encontra apegado à idéia de projeto, isto é, sua filosofia estaria ligada à realidade natural, e, por conseguinte, à realidade humana. Segundo o autor, o humanismo estaria, na década de 40, vivendo uma situação múltipla, pois era uma palavra capaz de designar as correntes filosóficas em vários sentidos, isto é, para ele, as pessoas eram humanistas, até mesmo alguns marxistas, que, sendo racionalistas clássicos, acabavam por ser humanistas numa forma de liberalismo. ${ }^{12}$

Todavia, apesar da imensa quantidade de filosofias se afirmarem humanistas, Sartre afirma que o existencialismo seria uma forma de humanismo, posto que, tais outras correntes, que reivindicavam este estatuto, fá-lo de duas formas principais: recusa de comprometer-se, num ponto de vista politico e social; mas recusa de comprometer-se filosoficamente.

O existencialismo, consoante Sartre, "reivindica para si o homem em geral, porque não chega a formular essa posição exigida pelos acontecimentos, e a única posição progressiva que conhecemos é a do marxismo." 13 Nesse sentido, aproxima-se imensamente do marxismo. Todavia, é a partir do conceito de liberdade que a diferenciação em relação ao marxismo se operou (embora não-convenha ressaltar neste ensaio). É preciso afirmar que o existencialismo, segundo Sartre, tem

12. SARTRE, Jean-Paul. O existencialismo é um humanismo. 2 ed. (trad. Vergílio Ferreira) Lisboa: Presença, 1964, p. 313.

13. SARTRE, Jean-Paul. O existencialismo .... p. 315. 
por objetivo dar ao homem uma dignidade, isto é, uma possibilidade, através da afirmação do conceito de liberdade, uma capacidade de autodeterminação, uma capacidade de legislar sobre si próprio, na valorização do "eu" no mundo; nesse sentido, segundo o autor, o existencialismo seria um humanismo, a partir do instante que defende a recusa total à submissão a valores impostos. Nessa perspectiva, o existencialismo i humanismo, para Sartre, assim que valoriza o conteúdo da liberdade do homem, não do seu agir, de scu fazer, tal qual o marxismo tradicional, mas do seu querer, num âmbito não das rclações entre os homens (questão que the foi certamente muito cara na aproximação com o marxismo, descjado a partir da década de 50).

Convém, antes de ingressar diretamente no conccito-chave do pensamento sartreano, a liberdade. investigar os questionamento formulados por Foucault. Em contrapartida, para o intelectual francês do Collège de France, o humanismo representava tão-somente uma forma de se encontrar no mundo filosófico, uma espécie de identidade que é capaz de garantir a qualquer teoria o status devido no âmbito acadêmico, posto que se dedica à compreensão efetiva do homem na realidade, todavia, para Foucault, o humanismo não consegue fugir, ao contrário do que sempre se acreditou, das mesmas indagações e dos mesmos obstáculos epistemológicos existentes no campo do pensamento, cujo marxismo the representou a essência teórica.

Nesse sentido, Foucault, em 16 de maio de 1966, por ocasião da publicação de sua clássica obra Les Mots et les Choses, concedera uma entrevista a Madeleine Chapsal de La Quinzaine Littéraire. afirmando drasticamente suas críticas a esse modelo de pensamento: "O humanismo foi uma maneira de resolver, em termos morais, axiológicos, reconciliatórios, os prohlemas que não se podia de modo algum resolvê-los. Você conhece a palavra Marx? A humanidade somente sc coloca problemas que ela pode resolver. Eu penso que se pode dizer: o humanismo finge resolver os problemas que ele não pode se colocar" 14 isto é, os problemas de relacionamento do homem e do mundo, o problema da realidade, o problema da

14. CHAPSAL, Madeleine. Entretien avec Michel Foucault. Dits et Ecrits (org. Daniel Defert et François Ewald). v. I Paris: Gallimard, 1994, p. 516. "L'humanisme a été une manière de résoudre. dans des termes de morale, de valeurs, de réconciliation, des problèmes que l'on nc pouvait pas résoudre du tout. Vous connaissez le mot de Marx? L'humanité ne se pose que de problèmes qu 'elle peut résoudre. Je crois qu on peut dire: l'humanisme feint de résoudre des problèmes qu'il ne peut pas se poser!' [trad. do autor] 
criação artística, da felicidade, e de todas as obsessões que não merecem absolutamente ser problemas teóricos.

De outro lado, noutra entrevista, intitulada L'homme est-il mort? ${ }^{15}$ Foucault questiona de maneira igualmente incisiva a questão das filosofias da consciência e, sobretudo, do humanismo. Entende que o humanismo seria uma noção muito antiga, que remonta à época de Montaigne, e que perpassou a história ocidental como se só tivesse nela ocorrido, a tal ponto de utilizar o humanismo como forma de distinguir a cultura dos outros, as culturas orientais ou islâmicas da cultura ocidental. Esse fato, segundo Foucault, afirma que o homem ocidental é capaz de se assustar quando encontra traços deste humanismo alhures. O humanismo, tal como ensinado no segundo grau, originado no século XVI, numa visão continuista, acabava por gerar inúmeros maus entendidos. Segundo o autor, em razão dessa historiografia tradicional, em que os classicistas teriam desenvolvido os temas da natureza humana, e que as ciências positivas permitiram conhecer o homem de maneira positiva, cientifica e racional, especialmente, pela biologia. a psicologia e a sociologia, sempre se imaginou que ao mesmo tempo o humanismo tinha sido a grande força que animava o desenvolvimento histórico e que ele, então, estaria sendo recompensado por esse desenvolvimento.

Todavia. Foucault entende que tudo isso faz parte da ordem da ilusão, ${ }^{16}$ quer dizer, o movimento humanista data somente do final do século XIX, e quando se olha mais detalhadamente os séculos XVI, XVII e XVIII, percebe-se que o homem não tem literalmente nenhum lugar, já que a cultura é ocupada por Deus, pelo mundo, pela semelhança das coisas, pelas leis do espaço, pelos corpos, pela imaginação, etc., mas o homem, mesmo, estaria ausente nesses séculos. O homem, ao contrário do que sempre se pensou, segundo Foucault, apesar de um cuidado moral, só se tornou um objeto de saber quando o conhecimento cientifico o tornou possivel, e todos os temas morais do humanismo contemporâneo apareceram. ${ }^{17}$ Nesse sentido, Foucault entende que o humanismo de Sartre, especialmente em sua obra Critique de la Raison

15. BONNEFOY, C. L'homme est-il mort?. Dits et Écrits (org. Daniel Defert et François Ewald). v. I Paris: Gallimard, 1994, p. 540-544.

16. BONNEFOY. C. L'homme .... p.540.

17. Nessa linha, ver: BEVIR, Mark. A humanist critique of the archacology of the human sciences. Rivista Storia della Storiografia, Milão, n. 32. p. 17-32, 1997. 
Dialectique seria um esforço magnífico, mas patético do homem do século XIX em pensar o século XX, sendo o último hegeliano e o último marxista.

Num belo texto publicado na Magazine Littéraire em 1984 e reeditado em 1993, tanto referido na temática sobre as bases filosófico-ontológicas de Foucault, o autor defende que o humanismo, totalmente distinto da Aufklärung, seria uma constante na história, ora marxista, ora existencialista, ora personalista, e que serviria para dar cor e para justificar simplesmente as concepções do homem ao qual ele se encontrava 'obrigado' a recorrer. Dessa maneira, o humanismo não poderia escrever sua singularidade como uma atitude crítica, tal como a Aufklärung. É nessa perspectiva, que ao denominar a sua filosofia como uma 'ontologia do presente' que Foucault rejeita o humanismo e se coloca na linha de Kant. ${ }^{18}$

É nesse sentido, portanto, que se pode pensar que as teorias de Foucault se opuseram, no início, aos questionamentos elaborados por Sartre, numa espécie até de rebeldia intelectual, em razão do domínio que o marxismo exercia na França, mas que nem mesmo o próprio Sartre conseguia definir-se claramente enquanto tal, especialmente a partir de seu conceito de liberdade. Dessa maneira, Foucault opõe um contrahumanismo, afirmando que seria indispensável se libertar dessa forma de humanismo até então praticada: "Nosso sistema não se ocupa de modo algum dos problemas referentes às relações do homem com o mundo, etc. Nosso objetivo principal, atualmente, é o de nos libertar definitivamente do humanismo e, nesse sentido, nosso trabalho é um trabalho político" 19

Todavia, é indispensável ressaltar que alguns autores, como o biógrafo de Sartre, Bernard-Henri Lévy, defendem que a questão humanista em seu autor pode ser garantida e excluída das manifestações políticas muito mais que as teorias de Foucault, que sucumbiram claramente aos movimentos da época. Nesse sentido, defende uma versatilidade de Sartre em fugir dos modismos, ao contrário do próprio Foucault: "Isso quer dizer que esse Sartre nos anuncia a tempos de paz eterna? Isso significa a volta, por intermédio desse anti-racismo e da des-essencialização dos conflitos a que ele permite proceder, dos velhos sonhos da humanidade pacificada,

18. FOUCAULT, Michel. Qu'est-ce que les lumières? ..., p. 70.

19. CHAPSAL, Madeleine. Entretien avec .... p. 516. "Notre système ne s'en occupe absolutment pas. Notre tâche actuellement est de nous affranchir définitivement del'humanisme, et, en ces sens, notre travail est un travail politique." [trad. do autor] 
sem qualquer conflito, que sabemos terem ligação com a vontade de pureza $e$, portanto, com o crime? Não. Pois é essa a força desse primeiro Sartre. É sua extrema originalidade e o inapreciável valor do seu discurso. Ele historiciza os conflitos, o que é hom. Ele os relativiza, o que é essencial. Ele consegue, melhor que Foucault, no momento mesmo em que Foucault cede a turvo fascínio do discurso da guerra das raças à maneira de Boulainvillies, desfazer-se do enfeitamento do discurso naturalista, e, portanto, extreminacionistas." 20"

Entretanto, a relação entre Foucault e Sartre se ameniza, até que os dois se encontram em 10 de fevereiro de 1969, como visto, por ocasião das drásticas medidas de expulsão e perseguição dos alunos 'sobreviventes' de 1968 da Universidade de Vincennes, para protestar contra o governo. ${ }^{21}$ Esse é o momento, também que se pode verificar além do reconhecimento foucaultiano da figura de Sartre, como também a valorização de ambos pelo conceito de liberdade. Segundo Poster, depois de maio de 1968 a gélida hostilidade de Foucault contra Sartre e o marxismo ocidental de um modo geral foi se desfazendo, a ponto de o novato intelectual reconhecer a importância de Sartre, chegando mesmo a adotar a sua posição no campo intelectual e politico parisiense. ${ }^{22}$ Nesse sentido, ambos os autores, começam a se questionar sobre o conceito de liberdade, o que, de certa forma, os aproxima, mas não é capaz de conceder uma identidade de pensamento, em virtude de uma sutil diferença sobre o fundamento da liberdade.

Regressando, assim, ao conceito de liberdade, é indispensável visualizálo em Sartre como uma "liberdade engajada" [engagée], isto é, a partir do instante em que $o$ individuo reconhece sua liberdade, única, acaba por reconhecer implicitamente a liberdade dos outros, no mundo, nas situações, nessa linha, afirma o autor: " $a$ liberdade é única, mas ela se manifesta diversamente conforme as circunstâncias" 23 Ao contrário dos deterministas, o ato livre, em Sartre, somente o será quando não houver motivo anterior para provocá-lo, ou seja, a decisão entre dois motivos de iguais valores não admite qualquer manifestação de resistência, e sempre será livre a

20. LÉVY, Bemard-Henri. O século de Sartre: inquérito filosófico. (trad. Jorge Bastos) Rio de Janeiro: Nova Fronteira, 2001 , p. 347.

21. ERIBON, Didier. Michel Foucault..., p. 191.

22. POSTER, Mark. Foucault, el marxismo ..., p. 17.

23. SARTRE. Jean-Paul. Situations, I: essais critiques. Paris: Gallimard, 1947, p. 289. 
partir do momento em que se credita uma afirmação de si, uma escolha de instante desligado do passado e de todas as suas relações causais. Nesse sentido, a liberdade existe no exato instante em que ele se exercita - uma autonomia do querer - ou seja, para Sartre, a liberdade não está nem relacionada à causalidade do passado, nem do que se deseja, mas sim, ao querer autonomamente, isto é, na capacidade de determinar o querer por si mesmo.

Nessa perspectiva, é possível pensar em Sartre certos paradoxos, como, por exemplo, ser livre enquanto confinado, pois para o autor, uma vez que a liberdade está na autonomia do qucrer, o simples fato de procurar querer projetar sua fuga já o torna livre, posto que, embora não consiga, essa impossibilidade não diz com o campo da liberdade do querer e do projetar, mas com o campo material, da realidade absoluta. Dessa maneira, qualquer resistência que a liberdade encontre, qualquer adversidade não é capaz de limitar a liberdade humana, a liberdade do 'querer', já que esta se refere antes à impossibilidade ao 'poder' Isso poderia fazer sugerir que a liberdade é indeterminada para Sartre, mas convém que outras questões sejam observadas.

Para o autor, não cabe aos homens escolherem a sua liberdade, uma vez que ele é nela lançado, e 'condenado a ser livre' ${ }^{24}$ condenado a existir para sempre além de sua essência, tal a máxima, desta maneira, a liberdade, embora fundamentada na autonomia do querer pode sempre encontrar uma única resistência, que não the vem do mundo exterior, mas de si própria.

Nesse sentido, a liberdade no seu reconhecimento individual implica o reconhecimento da liberdade dos outros, quer dizer, a liberdade não é indeterminada, mas engajada e só é livre porque cria uma determinada situação para o sujeito, mas não-totalmente, pois, e sendo engajada, está na dependência dos outros, de um outro estado de coisas. O sujeito é livre para determinar a si próprio, e só o é nesse caso em particular, na sua liberdade, no seu ato livre limitado por uma situação anterior, na situação de ligação do homem com o mundo.

Nessa perspectiva, é necessário destacar que o homem é livre, porque não aceita um constrangimento externo, isto é, o constrangimento das coisas, da situação, mas porque exercita no mundo sua liberdade, escolhe seu ser, mas porque aceita o constrangimento de ser, sim, livre, de estabelecer fins, de agir, etc. 
A respeito dessa limitação anterior, o filósofo português Virgílio bem esclarece: "se eu nasci burguês ou proletário, a minha 'liberdade determina-se pelo horizonte que se abre à minha condição de proletário ou burguês. Passo a reagir desta ou daquela maneira. Mas é como burguês ou proletário que reajo" 25

A partir do instante que não cabe à liberdade se escolher. uma vez que antes de escolher, o indivíduo já se escolhe para a escolha que iria fazer. pois quando a vontade intervém a decisão em ser livre já está tomada, ${ }^{20}$ verifica-se uma escolha anterior lançada no mundo; a sua limitação se encontra justamente no fato do indivíduo estar sempre em "situação". de não poder se ver livre da realidade, realidade essa de ser engajado. Dessa maneira, a liberdade só pode ser pensada, consoante Sartre, numa relação com o mundo, numa relação concreta, ${ }^{27}$ quer dizer. a liberdade não é, tal defendem os contratualistas, um direito, como outros tantos: de vida, à saúde, de propriedade, etc., ou mesmo uma qualidade, mas um exercício, igual a todos, ${ }^{28}$ uma arte que só tem sentido no mundo, numa situação, por isso, segundo Virgílio, a liberdade 'é sendo' ${ }^{29}$ A liberdade, não sendo uma propriedade do homem, é sua condição de possibilidade, vez que é justamente a liberdade que estrutura o

25. FERREIRA, Virgilio. Da fenomenologia a Sartre. Lisboa: Presença, 1964. p. 138.

26. SARTRE, Jean-Paul. L'être et ..., p. 527.

27. ROSENTHAL, Gérard; ROUSSET, David: SARTRE, Jean-Paul. Entretien sur la politique. Paris: Gallimard, 1949, p. 106. "Sartre . Pour moi la liberté de penser abstraitement-que l'on concéde aux électcurs et aux militants - n'est qu'une liberté abstraite. La seule liberté concréte de penser, c'est la liberté de penser concrètement (...) En un mot, la pensée concrète, c'est la pensée d'un groupe de producteurs ou de consommateurs, qui prend comme départ les nécessités et les exigences de la production dans l'entreprise dont ils font partie et de la consommation dans le cadre de leurs besoins et de leur pouvoir d'achat." |trad. do autor. "Sartre - Para mim, a liberdade de pensar abstratamente - que se concede aos eleitures e aos militares - é somente uma liberdade abstrata. A única liberdade concreta de pensar é a liberdade de pensar concretamente (...) numa única palavra, o pensamento concreto é o pensamento de um grupo de produtores ou consumidores que partem das necessidades e das exigèncias da produção na empresa das quais eles fazem parte, e o consumo na esteira de suas necessidades esen poder aquisitivo."]

28. SARTRE, Jean-Paul. Situations, I ..., p. 293. "Cette entière liberté. précisćmunt parce qu'elle né comporte pas de degrès, il est visible qu'elle apartient également à tout homme. Or plutôt car b liberé n'est pas une qualité parmi d'autres - il est visible que tout homme est liberté." [trad. (fo autor "É visivel que essa liberdade completa, precisamente porque não comporta niveis, é quc pertence igualmente a todo homem. Ora, preferencialmente, pois a liberdade não é uma qualidade entre outras, é visível que todo homem é livre.]

29. FERREIRA, Virgílio. Da fenomenologia ..., p. 141. 
homem, "é o único fundamento do ser" 30 porque o homem livre é aquele que exerce atos no mundo, na possibilidade de negar-se enquanto ser, transcender, projetar-se além de si próprio; a liberdade, portanto, na relação com o mundo, implica no próprio ato 'intensionar' de ser.

Essas concepções acerca da liberdade certamente adquirem o status central dentro dos questionamentos do autor, seja no âmbito filosófico, seja, sobretudo, no âmbito literário. Sartre se dedicou durante toda a década de 40 a escrever, além de outros textos como seu clássico L'Être et le Néant, L'Existencialisme est un Humanisme, a trilogia intitulada Les Chemains de la Liberté, composta pelos volumes La Mort dans l'Âme, Le Sursis, e sobretudo, na metade da década, $L \hat{A}$ ge de Raison. Esses textos foram, de fato, romances em torno da busca, da definição e da 'delimitação' da liberdade, que convém agora serem ressaltados.

Dessa maneira, adotando-se para análise o primeiro dos volumes da trilogia $L ' \hat{A} g e$ de Raison, por ser, sem dúvida, o mais significativo, dado que surgira no ano seguinte ao final da Segunda Guerra Mundial, e toda a necessidade de contestação, bem como para não se delongar muito na investigação da obra sartreana, convém fazer uma breve interpretação do texto, a fim de que o tema da liberdade ressalte aos olhos do leitor. Ademais, L'Âge de Raison traz em seu núcleo quase que as linhas-mestras do conceito de liberdade em Sartre: a questão da ausência de motivos, da liberdade no mundo, da liberdade da escolha marcada, etc.

L'Âge de Raison é um livro que demonstra a situação vivida pelo intelectual francês no período recém pós-guerra, tratando de temas até então inexplorados, como a homossexualidade, o uso de drogas, o aborto, a família monoparental, o engajamento político, etc., temas polêmicos que permitem os dezoito capítulos vivenciarem a teoria existencialista e as questões da política e da liberdade na sua máxima extensão e como "liberdade engajada" tal fora visto.

A obra gira em torno da personagem Mathieu Delarue, um jovem filósofo e professor que vai à busca da liberdade última, a liberdade sem presas, sem resistências, mas tem seu destino entrecruzado com Marcelle, sua companheira. $\mathrm{O}$ grande problema da liberdade se coloca para a personagem, a partir do instante que Mathieu descobre estar ela grávida, o que significaria, para a época, a necessidade do

30. SARTRE, Jean-Paul. Situations, I ..., p. 308. "l'unique fondement de l'être était la liberté." [trad. do autor. "... o único fundamento do ser era a liberdade."] 
casamento e a dedicação ao filho, formas que representariam, de fato, a negação de seu 'projeto' de sua liberdade. Dessa maneira, após se questionar excessivamente, Mathieu propõe a Marcelle que faça o aborto, todavia, falta-lhe dinheiro para tanto. É em busca do dinheiro que a questão da liberdade começa a se desvencilhar.

Mathieu então inicia a sua busca pelo dinheiro que, no fundo, é a busca de sua liberdade. Inicialmente, encontra-se com um antigo amigo, Brunet, a pessoa que the representa na vida o engajamento político, já que é essencialmente um proletário, uma pessoa direcionada para o questionamento da situação concreta em que vive. A liberdade está, pois, intimamente ligada ao engajamento, personificado em Brunet, a partir do instante que está comprometida com a ação. Apesar de titubear em seguir seu amigo, Mathieu não consegue fugir à sua condição primeira, àquilo que a pouco se fez citar Virgílio sobre a única limitação da liberdade, a impossibilidade de negar sua origem burguesa, sua classe. Nada conseguindo com Brunet, Mathieu segue ao encontro de outro "amigo", Daniel, um homossexual que também acaba por não ajudá-lo. Todavia, as passagens em torno da personagem de Daniel trazem à lume as teorias suprareferidas da liberdade como ausência de motivo, como liberdade pura, isto é, trata-se de uma personagem que representa a oposição sartreana aos deterministas. Isso é verificado quando Daniel estando em passeio com seus gatos, decide matá-los sem motivo algum, mas após pensar, desiste, demonstrando, assim, que tinha liberdade para fazer o que quisesse, a sua "autonomia do querer", outrora mencionada. Mais tarde, Mathieu descobre que, no fundo, Daniel tinha o dinheiro para lhe emprestar, mas não o fizera, pois queria ver seu "amigo" se casar com Marcelle e renunciar a sua própria liberdade.

Em virtude da negativa de Daniel, Mathieu segue sua busca, c, no caminho, encontra-se com Ivich, com quem descobre uma imensa paixão. Apesar da dúvida em relação a Marcelle, Mathieu não tem tempo de fazer sua escolha, embora tenha declarado abertamente o seu amor, já que lvich tem de deixar a cidade por haver reprovado no Bac. Nesse interim, vai pedir ajuda a Jacques, seu irmão, um burguês que permanecera estritamente fiel às suas origens, quando, então, este, indignado, responde-lhe que não o ajudaria, uma vez que ele já estaria na "idade da razão" logo, deveria se livrar de seu sonho adolescente de "liberdade", trabalhar, cuidar sozinho de sua vida, casar, e criar seu filho e todas as responsabilidades inerentes. Mesmo tendo repensado nas idéias de seu irmão, Mathieu não consegue seguir seus exemplo, pois isso lhe representaria a sua própria morte, e a morte para 
seus amigos, Brunet e Daniel, que fizeram da liberdade as suas condições de possibilidade no mundo.

É nesse instante que aparece Lola, uma cantora de relativo sucesso, que desperta a paixão de Mathieu, e de quem, por um ato desesperado pelo aborto, chega a lhe roubar algum dinheiro. Sem embargo toda a confusão com Lola, que suspeitara de seu amante Boris, Mathieu continha a procurar o dinheiro, mas com insucesso. Embora tenha se resignado e decidido casar-se com Marcelle, Mathieu. após lhe comunicar e dizer que não mais a amava, ela o põe para fora de casa e decide ter o filho sozinha. Todavia, nesse contexto, surge Daniel, que se propõe à Marcelle em ocupar o lugar de seu amigo, o que demonstra, para Mathieu, a maior de todas as renúncias, a renúncia de alguém que viveu pela busca da liberdade. Assim, termina L'Âge de Raison.

Em meio a essa narrativa, como já esboçado, ressaltam inúmeros monólogos elocubrados pelo professor de filosofia no seu choque com as personagens, que convêm serem revisitados aqui, para a melhor compreensão do tema da liberdade em Sartre. Nesse sentido, no terceiro capítulo, quando o verão vem brindar a vida de Mathieu, e ele está com Marcelle grávida, sem dinheiro algum para lhe tirar o filho, então se pergunta num solilóquio angustiante: "Mas quer ser livre, como outros desejam uma coleção de selos. A liberdade é seu jardim secreto. Sua pequena convivência para comigo mesmo" ${ }^{31}$ Adiante, quando Mathieu refletia, cansado, e com as mãos sobre os olhos, uma bola de tênis rolara aos seus pés, que a devolvera, num calor 'abafante', e, preocupado com a sua situação financeira, repetia incansavelmente: "Ser livre. Ser causa de si próprio, poder dizer: sou porque quero; ser o próprio começo." 32 Ainda num lamento desvairado, Mathieu se pergunta quase que desistindo novamente: "Por quê não tive vontade de lutar? Poderia escolher outro mundo? Sou ainda livre?" ${ }^{33}$ e aqui se apresenta, neste texto literário, o

31. SARTRE, Jean-Paul. Les chemins de la liberté: l'âge de raison. Paris: Gallimard, 1945, p. 54. “il veut êtrc libre, comme d'autres veulent une collection de timbres. La liberté, c'est son jardin secret. As petite connivence avec lui-même." [trad. do autor]

32. SARTRE, Jean-Paul. Les chemins de la liberté: I'âge ..., p. 55-56. "Être libre. Être libre cause de soi. pouvoir dire: je suis parce que je le veux; être mon propre commencement." [trad. do autor]

33. SARTRE. Jean-Paul. Les chemins de la liberté: l'âge ..., p. I20. "Pourquoi n’ai-je pas eu envie d'aller me battre? Est-ce que j'aurais pu choisir un autre monde? Est-ce que je suis encore libre?" [trad. do autor] 
questionamento feito em 1943 por Sartre em sua clássica obra, sobre os individuos se estarem lançados no mundo e na liberdade, sem poder refutá-los.

A presença da vontade de liberdade, em Mathieu, demonstrava-se nas situações mais simples da vida, sobretudo na possibilidade de contestação, quando, em conversa com Brunet, já cansado pela busca cotidiana em ser livre, questiona-se a liberdade: "Não tenho nada a defender; não me envaideço de minha vida e não tenho nenhum dinheiro. Minha liberdade? Ela me pesa. Há anos sou livre à toa. Morro de vontade de trocá-la por convicção. (...) Recusei porque quero ser livre" 34

Todavia, o grande questionamento acerca da liberdade primeira, sem motivos, natural, responsável e do querer autônomo, surge quando a personagem Boris, ao recusar o comunismo na Faculdade por conta de Mathieu, constrói sua vida sobre a liberdade, segundo a narrativa de Sartre: "Na aula de Filosofía, sentira-se atraido pelo comunismo, mas Mathieu o desviara ensinando-lhe o que era a liberdade. Boris compreendera imediatamente: é um dever-fazer o que se quer, pensar o que se bem entende, ser responsável perante si próprio apenas, analisar permanentemente o que se pensa e todo o mundo. Boris construira sua vida sobre esses alicerces. Era escrupulosamente livre (...) Quanto à liberdade, não era recomendável analisá-la em demasia, porque a gente dcixava então de ser livre" 35 Por fím, a última grande questão da liberdade, a liberdade como mito, coloca-se para Sartre, quando Mathieu, tendo a possibilidade de pegar o dinheiro e desistido, reflete insistentemente: "Não pude pegar o dinheiro, minha liberdade é um mito e minha vida constrói-se por debaixo desse mito com um rigor mecianico, um vazio, o sonho

34. SARTRE, Jean-Paul. Les chemins de la liberté: l'âge ..., p. 131. "Je n"ai rien à défendru: je ne suis pas fier de ma vie et je n'ai pas le soi. Ma liberté? Elle me pèse: voilà des années que je suis libre pour rien. Je crève d'envie de la troquer un bom coup contre une certitude. (...) J'ai reffusé parce que je veux rester libre." [trad. do autor]

35. SARTRE, Jean-Paul. L es chemins de la liberté: l'âge ..., p. 146. “... en classe de philosophie, il avait eu de vives sympathies pour le communisme et Mathieu l'en avait détourné en lui expliquant ce que c'était que la liberté. Boris avait tout de suite compris: on a le devoir de faire tout ce qu'on veut. de penser tout ce qui vous semble bon, de n'être responsable que devant soi-même et de remettre en question, constamment, tout ce qu'on pensc et tout le monde. Boris avait bâti sa vie là-dessus et il étart scrupuleusement libre. (...) Quant à la liberté, il n'était pas bon non plus de s'interroger sur elle, parce qu'alors on cessait d'être libre." [trad. do autor] 
orgulhoso e sinistro de não ser nada, de ser sempre outra coisa diferente do que sou" 36

A relação de Sartre com Foucault, em torno da liberdade, pode ser conduzida pela interpretação feita por Gerd Bornheim, em 1971, de que "a negação interna do para-si fez da liberdade um incondicionado e absoluto: a liberdade se torna sinônimo de lihertação da subjetividade" ${ }^{37}$ Nesse sentido, a necessidade da liberdade como forma de subjetivação em Sartre, permite aproximar-se de Foucault ou, ao contrário, a partir do instante que a liberdade neste autor, como outrora visto, impõe-se como requisitos para a constituição de uma nova forma de subjetividade, uma subjetividade igualmente livre, sem dominação, sem efeitos da normalização. ou seja, se Sartre defende a liberdade na situação, no mundo, Foucault da mesma forma a concebe, em exigências concretas, como dos amotinados em prisões francesas ou como a oposição existencialista dos dissidentes do leste europeu, etc. Todavia, há uma pequena diferença que os distancia novamente, que diz respeito à ordem novamente em razão da opção inicial do humanismo, pois para Foucault, e de certa forma há aqui uma aproximação maior com Heidegger, a liberdade não como escolha fundamental sobre quem somos, mas como libertação das possibilidades de uma época.

A liberdade em Foucault está intimamente relacionada ao cuidado de si, quer dizer, às técnicas de dominação de si, o que leva ao seguinte entendimento: a liberdade não deve ser vista como um fim da dominação ou como a remoção da história, mas a revolta pela qual a história pode ser a cada passo transformada ${ }^{38} \mathrm{de}$ maneira real e não-funcional. Ao contrário do humanismo de Sartre, em que a liberdade só existe no mundo, tanto que a ela o indivíduo é lançado e se encontra condenado, para Foucault, a liberdade se exercita, mas antes no próprio indivíduo do que no mundo, antes como um bom uso de seus prazeres, que o uso e o prazer dos outros, antes uma tecnologia de si, do que um cuidado do outros. que só ocorre em segundo plano. A liberdade, embora politica, não é necessariamente engajada, posto que existe no próprio indivíduo com relação aos outros. É política porque são práticas

36. SARTRE, Jean-Paul. Les chemins de la liberté: l'âge ..., p. 224. "Je n'ai pas pu prendre l'argent; ma liberté c'est um mythe. Un mythe et ma vic se construir par en dessous avec une rigueur mécanique. Un néant, le Rêre orgueiller et sinistre de n'êrre rien, d'ĉtre toujours autre chose que ce que je suis." [trad. do autor]

37. BORNHEIM. Gerd. Sartre. São Paulo: Perspectiva, 1971, p. 113-114.

38. RAJCHMAN, John. Foucault: a liberdade .... p. 40. 
de liberdade, enquanto que a liberação, como da sexualidade, é condição política para a existência dessas práticas. A liberdade não é um modo de condução de vida, ligado ao exercício das funções políticas, mas é antes uma ética que visa a responder a seguinte pergunta: Como se pode praticar a liberdade? A liberdade é, portanto, um ethos, uma maneira de ser e de se conduzir que está antes dirigida ao indivíduo que ao seu âmbito político propriamente dito.

Dessa maneira, se enquanto a liberdade para Sartre, de raizes evidentemente marxistas, implica o reconhecimento da liberdade dos outros ao estabelecer a liberdade individual, não sendo jamais indeterminada, mas engajada, já que cria uma determinada situação para o sujeito na dependência direta dos outros ou do estado de coisas, para Foucault a liberdade é um exercício antes individual, no uso de seus prazeres, num âmbito micro, não-relacionado diretamente às massas.

São Paulo, maio de 2004.

3. Referências Bibliográficas

BEVIR, Mark. A humanist critique of the archaeology of the human sciences. Rivista Storia della Storiografia, Milão, n. 32, p. 17-32, 1997.

BONNEFOY, C. L'homme est-il mort?. Dits et Écrits (org. Danicl Defert et François Ewald). v. 1 Paris: Gallimard, 1994, p. 540-544.

BORNHEIM, Gerd. Sartre. São Paulo: Perspectiva, 1971, 319 p.

CHAPSAL, Madeleine. Entretien avec Michel Foucault. Dits et Écrits (org. Daniel Defert et François Ewald). Paris: Gallimard, 1994. v. 1. p. 513-518.

DELEUZE, Gilles. Les intellectuels et le pouvoir: entretien avec Michcl Foucault. Dits et Écrits (org. Daniel Defert et François Ewald). Paris: Gallimard, v. 2, 1994, p. 306-315. [trad. br. Os intelectuais e o poder. Microfísica do poder. (trad. Roberto Machado) 13 ed. Rio de Janeiro: Graal, 1998, p. 69-78.]

ELKABBACH, Jean-Pierre. Foucault répond à Sartre. Dits et Écrits (org. Daniel Defert et François Ewald). v. 1 Paris: Gallimard, 1994, p. 662-668. 
ERIBON, Didier. Michel Foucault. (trad. Hildegard Feist). São Paulo: Companhia das Letras, 1990, 351p.

Michel Foucault e suus contemporâneos. (trad. Lucy Magalhães) Rio de Janeiro: Jorge Zahar, 1996, 244p.

FERREIRA. Virgílio. Da fenomenologia a Sartre. Lisboa: Presença, 1964. p. 5-230

FOUCAULT, Michel. Qu'est-ce que les lumières? Magazine Littéraire, Paris, n. 09, avril. p. 61-73, 1993. [trad. al. Was ist aufklärung?. Ethos der Moderne: Foucaults Kritik der Aufklärung. (org. Lva Erdmann, Rainer Forst e Axel Honneth) Frankfurt: Campus Verlag, 1990, p. 35-54.]

LFBRUN, Gérard. Nota sobre la fenomenologia contenida en las palabras y' las cosas. Michcl Foucault, filosófo. (trad. Alberto Luis Bixio) Barcelona: (iedisa. 1999. p. $31-47$.

LÉVY, Bernard-Henri. O século de Sartre: inquérito filosófico. (trad. Jorge Bastos) Rio de Janeiro: Nova Fronteira, 2001. 570 p.

POSTER. Mark. Foucault, el marxismo y la historia. (trad. Ramón Alcalde) Barcelona: Paidós, 1987. 228 p.

RIBEIRO, Renato Janinc. O intelectual e seu outro: Foucault e Sartre. Revista de Sociologia da USP Tempo Social, São Paulo, v. 7, n. 1-2, p. 163-174, out. 1995.

ROSENTHAL, Gérard; ROLSSET, David; SARTRE, Jean-Paul. Entretien sur la politique. Paris: Gallimard, 1949. $219 \mathrm{p}$.

SARTRE, Jean-Paul. Critique de la raison diulectique: théorie des ensenbles pratiques. v. I. Paris: Gallimard, 1960. 755 p.

. L'ètre et le néant. Paris: Gallimard, 1943.

Les chemins de la liberté: l'âge de raison. Paris: Gallimard, 1945. 315 p.

$O$ existencialismo é um humanismo. 2 ed. (trad. Vergílio Ferreira) Lisboa:

Presença. 1964. p. 23I-330.

Situations, 1: essais critiques. Paris: Gallimard, 1947. 308 p. 